University of Massachusetts Amherst

ScholarWorks@UMass Amherst

Chemistry Department Faculty Publication Series

Chemistry

1986

\title{
A Variable Dispersion Flow Injection Manifold for Calibration and Sample Dilution in Flame Atomic Absorption Spectrometry
}

Julian Tyson

University of Massachusetts Amherst

James R. Mariara

Loughborough University of Technology

J.M.H. Appleton

Loughborough University of Technology

Follow this and additional works at: https://scholarworks.umass.edu/chem_faculty_pubs

Part of the Chemistry Commons

\section{Recommended Citation}

Tyson, Julian; Mariara, James R.; and Appleton, J. M.H., "A Variable Dispersion Flow Injection Manifold for Calibration and Sample Dilution in Flame Atomic Absorption Spectrometry" (1986). Journal of Analytical Atomic Spectrometry. 1376.

Retrieved from https://scholarworks.umass.edu/chem_faculty_pubs/1376 


\title{
A Variable Dispersion Flow Injection Manifold for Calibration and Sample Dilution in Flame Atomic Absorption Spectrometry
}

\author{
Julian F. Tyson, James R. Mariara and John M. H. Appleton \\ Department of Chemistry, University of Technology, Loughborough, Leicestershire LE11 3TU, UK
}

\begin{abstract}
A flow injection (FI) introduction system for flame atomic absorption spectrometry (FAAS) has been constructed for single-standard calibration and sample dilution. Dilution factors ranaina from 5.93 to 38.8 in six discrete stages were produced by replicate injection of $12.5-\mu \mathrm{l}$ volumes into an aqueous carrier stream flowing down lines of different lengths. The dilution factors were measured for five different solutions for each line. No dependence on concentration was found and the relative standard deviations ranged from 0.75 to $3.1 \%$. The manifold was evaluated by the analysis of solutions of magnesium $(6,12.5$ and 35 p.p.m. $)$, nickel (180 p.p.m.), calcium (75 p.p.m.) and chromium (180 p.p.m.). Recoveries ranging from 95.3 to $106.8 \%$ were obtained with no over-all evidence of bias. The uncertainty in the over-all method, including a contribution from the curve-fitting procedure, was estimated to be $5 \%$.
\end{abstract}

Keywords: Flow injection analysis; flame atomic absorption spectrometry; calibration; sample dilution

Flow injection (FI) techniques have been used for a wide variety of sample and standard manipulations prior to measurement by flame atomic absorption spectrometry (FAAS). ${ }^{1}$ Recent examples of such manipulations include pre-concentration and clean-up using ion exchange, ${ }^{2}$ solvent extraction ${ }^{3}$ and vapour generation. ${ }^{4}$ Flow injection manifolds for speciation studies $^{5}$ and indirect methods 6 have also recently been reported. The use of FI techniques for producing solutions for calibration purposes has been described $^{1}$ and preliminary results for methods that generate calibration data from a single concentrated standard have been reported. 7,8 Branched manifolds have been used for dilution purposes for solution spectrophotometry. ${ }^{9,10}$ This paper describes the use of a variable dispersion coefficient manifold that produces six discrete dilution factors for calibration and dilution of off-range samples.

\section{Experimental}

\section{Apparatus}

A constant displacement pump (Sage Instruments Model $341 \mathrm{~A}$ syringe pump) was used. With a $30-\mathrm{ml}$ syringe this produced flow ranges covering the nominal range $0.23-8.8$

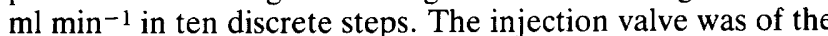
rotary type with an external sample loop (Rheodyne Model $5020)$. The valve was modified by removal of the two connecting tubes to the external loop and substitution of a single length of $0.7 \mathrm{~mm}$ i.d. PTFE tubing of volume $12.5 \mu \mathrm{l}$. The manifold consisted of six lines in parallel between two six-way switching valves (Rheodyne Model 5011). The dimensions of the lines are given in Table 1 . For convenience, the injection and stream-switching valves and six connecting lines were mounted in an enclosed aluminium box. The connections from the box to the atomic absorption spectrometer nebuliser

Table 1. Flow-rates in each line

\begin{tabular}{cccc}
$\begin{array}{c}\text { Line } \\
\text { number }\end{array}$ & $\begin{array}{c}\text { Tubing dimensions } \\
(\text { length } / \\
\mathrm{cm} \times \mathrm{i} . \mathrm{d} . / \mathrm{mm})\end{array}$ & $\begin{array}{c}\text { Mean rate of flow } \\
(n=5) / \mathrm{ml} \mathrm{min}^{-1}\end{array}$ & $\begin{array}{c}\text { Standard deviation/ } \\
\mathrm{m} \mathrm{min}^{-1}\end{array}$ \\
1 & $6 \times 0.7$ & 5.35 & 0.029 \\
2 & $18 \times 1.1$ & 5.32 & 0.028 \\
3 & $26 \times 1.1$ & 5.41 & 0.029 \\
4 & $60 \times 1.1$ & 5.32 & 0.037 \\
5 & $131 \times 1.1$ & 5.31 & 0.057 \\
6 & $229 \times 1.1$ & 5.33 & 0.030 \\
\hline
\end{tabular}

capillary, was by the minimum length $(20.6 \mathrm{~cm})$ of $0.57 \mathrm{~mm}$ i.d. PTFE tubing. The complete apparatus is shown in Fig. 1. The spectrometer was a Shandon Southern Model A3300 and the output was monitored with a Philips Model AR55 chart recorder. In all experiments the carrier stream was triply distilled water.

\section{Procedure}

\section{Flow-rate effects}

The spectrometer was optimised for maximum sensitivity for magnesium and the steady-state and flow injection response measured as a function of flow-rate setting on the pump (2.2, $3.3,5.5$ or $8.8 \mathrm{ml} \mathrm{min}^{-1}$ ) for a variety of nebuliser capillary positions. A suitable combination of flow-rate setting and capillary position was selected to give an optimum with respect to signal to noise ratio and minimim variation of signal with flow-rate. The flow-rate through each of the six lines was measured by weighing the amount of distilled water carrier delivered to the nebuliser capillary (the connection between the flow injection manifold and instrument being broken at this point to allow convenient collection of carrier stream in a receiving vessel), over an accurately timed interval. The flow-rate in $\mathrm{ml} \mathrm{min}^{-1}$ was calculated assuming the specific gravity of water to be unity. Five replicate measurements were made for each line, the means and standard deviations calculated and the results examined for significant differences between the average values.

\section{Dispersion coefficient measurement}

A steady-state calibration for magnesium was made over the range $0-1.2$ p.p.m. Five solutions of different concentrations were injected for each line. The mean absorbance of the

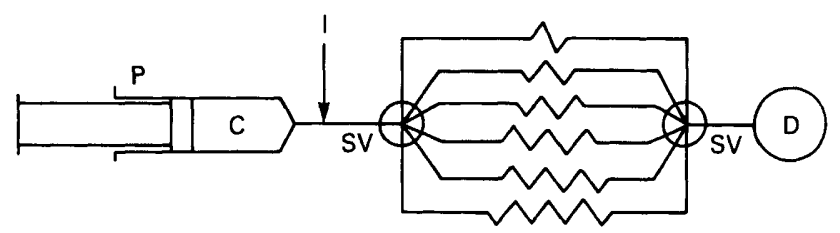

Fig. 1. Schematic diagram of apparatus used. C, Carrier stream (water); D, atomic absorption spectrometer; I, injection valve; $\mathrm{P}$, syringe pump; SV, 6-way switching valve. A detailed description of the apparatus is given in the text 
replicate injections for each concentration was calculated and the corresponding concentration found from the calibration plot by interpolation. Division of the original injected concentration by this value yielded a value for the dispersion coefficient. A line of regression of dispersion coefficient on injected concentration was calculated by the method of least squares and the $95 \%$ confidence interval for the slope calculated. The mean, standard deviation and $95 \%$ confidence interval about the mean of the dispersion coefficient for each line was calculated.

Use of manifold for calibration and dilution of off-range samples

A calibration for magnesium was obtained from a 5 p.p.m. stock standard solution by injection and switching down each of the six lines in turn. Solutions containing 6,12.5 and 30 p.p.m. of magnesium were analysed by injection down an appropriate line. The concentration corresponding to the peak maximum found from the calibration graph was used to calculate the injected concentration from the known dispersion coefficient value of the line used. The uncertainty in the final calculated value due to the uncertainty of the peak height and of the dispersion coefficient value was calculated. The procedure was repeated with nickel as the test element (calibration obtained from 300 p.p.m., test solution 180 p.p.m.), with calcium (calibration with 100 p.p.m., test solution 75 p.p.m.) and chromium (calibration 250 p.p.m., test solution 180 p.p.m.).

\section{Results and Discussion}

\section{Flow-rate Effects}

Maximum sensitivity was obtained with the position of the nebuliser capillary set to give the maximum pressure drop along its length and hence the maximum "natural" uptake rate. In agreement with previous studies, 8 steady-state responses showed a greater variation with flow-rate than did the corresponding FI peak heights. The flow-rate setting of 5.5 $\mathrm{ml} \mathrm{m^{-1 }}$ on the pump was chosen for all further work as this value fell within a plateau on the peak-height absorbance versus flow-rate response curve. The measured flow-rate through each of the six lines is shown in Table 1. Application of the $F$-test shows no significant difference between the variances at the $95 \%$ confidence level. Application of the $t$-test shows only one pair of means to have a significant difference at the $95 \%$ confidence level namely those for lines 2 and 3 . However, there is no evidence that as the line length increases, there is any decrease in flow-rate due to the increased back pressure in the system. It was thus assumed that the response of the spectrometer to any given concentration would be the same regardless of which line was used to deliver the solution to the spectrometer. The independence of flow-rate and tube length will be sustained when the manifold is connected to the instrument due to the negative pressure applied by the nebuliser. This is a feature unique to atomic absorption spectrometers and thus flow-rates essentially independent of tube length may not be obtained with other detectors such as spectrophotometers.

Table 2. Dispersion coefficient measurements for each line

\begin{tabular}{|c|c|c|c|c|c|c|}
\hline $\begin{array}{c}\text { Line } \\
\text { number }\end{array}$ & $C_{\mathrm{m}}$, p.p.m. & $D$ & Mean $D$ & $\begin{array}{c}95 \% \text { Confidence } \\
\text { interval }\end{array}$ & $\begin{array}{l}\text { Standard } \\
\text { deviation }\end{array}$ & $\begin{array}{c}\text { Relative } \\
\text { standard } \\
\text { deviation, } \%\end{array}$ \\
\hline 1 & $\begin{array}{l}1 \\
2 \\
3 \\
4 \\
5\end{array}$ & $\begin{array}{l}6.06 \\
5.83 \\
5.89 \\
5.98 \\
5.88\end{array}$ & 5.93 & \pm 0.11 & 0.091 & 1.5 \\
\hline 2 & $\begin{array}{l}2 \\
3 \\
4 \\
5 \\
6\end{array}$ & $\begin{array}{l}9.09 \\
8.77 \\
8.42 \\
8.47 \\
8.62\end{array}$ & 8.67 & \pm 0.34 & 0.27 & 3.1 \\
\hline 3 & $\begin{array}{l}3 \\
4 \\
5 \\
6 \\
8\end{array}$ & $\begin{array}{l}10.45 \\
10.39 \\
10.35 \\
10.26 \\
10.28\end{array}$ & 10.35 & \pm 0.10 & 0.078 & 0.75 \\
\hline 4 & $\begin{array}{r}5 \\
6 \\
8 \\
10 \\
12\end{array}$ & $\begin{array}{l}15.15 \\
14.29 \\
15.27 \\
14.93 \\
14.71\end{array}$ & 14.87 & \pm 0.48 & 0.39 & 2.6 \\
\hline 5 & $\begin{array}{r}8 \\
10 \\
12 \\
15 \\
20\end{array}$ & $\begin{array}{l}26.49 \\
25.51 \\
26.03 \\
25.86 \\
26.04\end{array}$ & 25.99 & \pm 0.44 & 0.35 & 1.3 \\
\hline 6 & $\begin{array}{l}12 \\
15 \\
20 \\
25 \\
30\end{array}$ & $\begin{array}{l}40.00 \\
38.46 \\
38.46 \\
38.64 \\
38.66\end{array}$ & 38.84 & \pm 0.81 & 0.65 & 1.7 \\
\hline
\end{tabular}




\section{Dispersion Coefficient Measurement}

The dispersion coefficient, $D$, of a flow injection manifold is defined as $D=C_{\mathrm{m}} / C_{\mathrm{p}}$ where $C_{\mathrm{m}}$ is the injected concentration and $C_{\mathrm{p}}$ is the concentration at the peak. For many FI systems the dispersion coefficient is conveniently measured as the ratio of instrument responses to concentrations $C_{\mathrm{m}}$ and $C_{\mathrm{p}}$. However, as has been pointed out ${ }^{1}$ and discussed in some detail, ${ }^{11}$ an atomic absorption spectrometer acts as a non-ideal detector. To account for the deviation from linearity of the response - concentration relationship, the response corresponding to the peak maximum is converted into concentration via the steady-state calibration function before calculation of the dispersion coefficient. The results of the measurements of the values of $D$ for each line are given in Table 2 . The results for the line of regression calculations are given in Table 3. The data used are those of columns 2 and 3 in Table 2. The $95 \%$ confidence intervals for the value of the slopes of the

Table 3. Results of regression line calculations

\begin{tabular}{cllcc}
$\begin{array}{c}\text { Line } \\
\text { number }\end{array}$ & \multicolumn{1}{c}{ Slope } & $s_{y / x}{ }^{*}$ & $\begin{array}{c}\text { Standard } \\
\text { deviation } \\
\text { of slope }\end{array}$ & $\begin{array}{c}95 \% \\
\text { Confidence } \\
\text { interval }\end{array}$ \\
1 & -0.02099 & 0.0983 & 0.031 & 0.099 \\
2 & -0.1240 & 0.214 & 0.058 & 0.19 \\
3 & -0.03621 & 0.0412 & 0.011 & 0.035 \\
4 & -0.006098 & 0.448 & 0.078 & 0.25 \\
5 & -0.1170 & 0.405 & 0.043 & 0.14 \\
6 & -0.04779 & 0.637 & 0.044 & 0.14
\end{tabular}

* The statistic $s_{y / x}$ is calculated from

$$
(n-2) s^{2}{ }_{y i x}=\Sigma\left(y_{\mathrm{i}}-\hat{y}\right)^{2}
$$

where $n$ is the number of points, $y_{\mathrm{i}}$ is an individual $y$-value (dispersion coefficient in this instance) and $\hat{y}$ is the $y$-value of the point on the regression line corresponding to $x_{\mathrm{i}}$ (concentration in this instance). ${ }^{12}$

Table 4. Results of calibration for magnesium; injected concentration 5 p.p.m.

$\begin{array}{ccccc}\begin{array}{c}\text { Line } \\ \text { number }\end{array} & \begin{array}{c}\text { Dispersion } \\ \text { coefficient }\end{array} & \begin{array}{c}\text { Peak } \\ \text { absorbance }\end{array} & \begin{array}{c}\text { Standard } \\ \text { deviation } \\ \text { of absorbance }\end{array} & \begin{array}{c}\text { Calculated } \\ \text { concentrations } \\ \text { at peak, } \\ \text { p.p.m. }\end{array} \\ 1 & 5.93 & 0.723 & 0.010 & 0.84 \\ 2 & 8.67 & 0.519 & 0.014 & 0.58 \\ 3 & 10.4 & 0.422 & 0.009 & 0.48 \\ 4 & 14.9 & 0.272 & 0.007 & 0.34 \\ 5 & 26.0 & 0.156 & 0.002 & 0.19 \\ 6 & 38.8 & 0.100 & 0.005 & 0.13\end{array}$

regression lines include the value 0 for all lines except number 3 , and thus the value of dispersion coefficient is taken to be independent of the concentration of the injected solution.

If the response time of the spectrometer was slow compared with the rise time of the FI peak, then it might be expected that the instrument would not follow a large rapid change in concentration at the nebuliser input and thus higher injected concentrations would give rise to an apparently higher dispersion coefficient value. In fact, at first sight, the results obtained suggest an opposite trend as all the regression lines obtained by the least-squares procedure have a negative slope. This would imply that as the injected concentration increased, the measured dispersion coefficient decreases. However, the $95 \%$ confidence intervals of the slopes show that this negative value is not statistically significant.

\section{Calibration and Dilution}

The results for the magnesium calibration based on the injection of 5 p.p.m. down each line are given in Table 4 . The calibration data generated were plotted and a curve fitted to the points manually. This curve was used for the analysis of three solutions whose concentrations were well in excess of the top of the conventional calibration range. The results are shown in Table 5. A first estimate of the relative standard deviations (RSD) of the calculated values may be obtained by compounding the RSD values for the absorbance measurements and the dispersion coefficient values. This gives values between 1.5 and $3.2 \%$, which are slightly higher than values obtained from a conventional procedure as the uncertainty in the dispersion coefficient values are greater than in the dilution factor obtained when volumetric glassware is used for dilution purposes.

The calibration data for nickel, calcium and chromium are given in Table 6 and the results for the analysis of off-range solutions of these elements are given in Table 7. An assessment of whether any bias is shown by the method requires an accurate calculation of the uncertainty in the calculated concentration. In addition to the two factors used above, namely the uncertainty in the measured peak height and in the value of the dispersion coefficient, the uncertainty due to the curve-fitting procedure needs to be taken into account. Estimates of the error due to manual curve-fitting procedures have been made, ${ }^{13}$ when it was found that for the elements $\mathrm{Mg}, \mathrm{Cr}$ and $\mathrm{Ni}$, the value was $\mathrm{ca}$. $4 \%$. Thus the over-all uncertainty may be of the order of $5 \%$. To check for bias this value would need to be converted into a $95 \%$ (or

Table 5. Analysis of off-range magnesium solutions

$\begin{array}{cccccc}\begin{array}{c}\text { Line } \\ \text { number }\end{array} & \begin{array}{c}\text { Dispersion } \\ \text { coefficient }\end{array} & \begin{array}{c}\text { Peak } \\ \text { absorbance }\end{array} & \begin{array}{c}\text { Calculated } \\ \text { concentration, } \\ \text { p.p.m. }\end{array} & \begin{array}{c}\text { Injected } \\ \text { concentration, } \\ \text { p.p.m. }\end{array} & \text { Recovery, \% } \\ 4 & 14.9 & 0.342 & 6.10 & 6.00 & 101.7 \\ 4 & 14.9 & 0.718 & 12.5 & 12.5 & 100.0 \\ 5 & 26.0 & 0.418 & 12.4 & 12.5 & 99.2 \\ 6 & 38.8 & 0.732 & 33.8 & 35.0 & 96.6\end{array}$

Table 6. Calibration data for injections of nickel (300 p.p.m.), calcium (100 p.p.m.) and chromium (250 p.p.m.)

\begin{tabular}{|c|c|c|c|c|c|c|c|}
\hline \multirow[b]{2}{*}{$\begin{array}{c}\text { Line } \\
\text { number }\end{array}$} & \multirow[b]{2}{*}{$\begin{array}{l}\text { Dispersion } \\
\text { coefficient }\end{array}$} & \multicolumn{2}{|c|}{$\mathrm{Ni}$} & \multicolumn{2}{|c|}{$\mathrm{Ca}$} & \multicolumn{2}{|c|}{$\mathrm{Cr}$} \\
\hline & & $\begin{array}{c}\text { Peak } \\
\text { absorbance }\end{array}$ & $\begin{array}{c}\text { Calculated } \\
\text { concentration, } \\
\text { p.p.m. }\end{array}$ & $\begin{array}{c}\text { Peak } \\
\text { absorbance }\end{array}$ & $\begin{array}{c}\text { Calculated } \\
\text { concentration, } \\
\text { p.p.m. }\end{array}$ & $\begin{array}{c}\text { Peak } \\
\text { absorbance }\end{array}$ & $\begin{array}{c}\text { Calculated } \\
\text { concentration, } \\
\text { p.p.m. }\end{array}$ \\
\hline 1 & 5.93 & 0.982 & 50.6 & 0.836 & 16.9 & 0.502 & 42.2 \\
\hline 2 & 8.67 & 0.862 & 34.6 & 0.602 & 11.5 & 0.348 & 28.8 \\
\hline 3 & 10.4 & 0.819 & 28.8 & 0.510 & 9.62 & 0.292 & 24.0 \\
\hline 4 & 14.9 & 0.642 & 20.1 & 0.364 & 6.71 & 0.203 & 16.8 \\
\hline 5 & 26.0 & 0.423 & 11.5 & 0.210 & 3.85 & 0.104 & 9.62 \\
\hline 6 & 38.8 & 0.305 & 7.73 & 0.154 & 2.58 & 0.072 & 6.44 \\
\hline
\end{tabular}


Table 7. Analysis of off-range solutions of nickel, calcium and chromium

\begin{tabular}{|c|c|c|c|c|c|c|c|c|c|c|}
\hline & & Element & & & $\begin{array}{c}\text { Line } \\
\text { number }\end{array}$ & $\begin{array}{l}\text { Dispersion } \\
\text { coefficient }\end{array}$ & $\begin{array}{c}\text { Peak } \\
\text { absorbance }\end{array}$ & $\begin{array}{c}\text { Calculated } \\
\text { concentration, } \\
\text { p.p.m. }\end{array}$ & $\begin{array}{c}\text { Injected } \\
\text { concentration, } \\
\text { p.p.m. }\end{array}$ & Recovery, \% \\
\hline $\mathrm{Ni}$ & . & $\cdots$ & . & . & $\begin{array}{l}2 \\
4 \\
6\end{array}$ & $\begin{array}{l}8.67 \\
14.9 \\
38.8\end{array}$ & $\begin{array}{l}0.675 \\
0.452 \\
0.192\end{array}$ & $\begin{array}{l}186 \\
186 \\
178\end{array}$ & $\begin{array}{l}180 \\
180 \\
180\end{array}$ & $\begin{array}{r}103.3 \\
103.3 \\
98.9\end{array}$ \\
\hline $\mathrm{Ca}$ & . & . & . & . & $\begin{array}{l}1 \\
2 \\
4 \\
6\end{array}$ & $\begin{array}{c}5.93 \\
8.67 \\
14.9 \\
38.8\end{array}$ & $\begin{array}{l}0.691 \\
0.470 \\
0.264 \\
0.110\end{array}$ & $\begin{array}{l}80.1 \\
76.3 \\
71.5 \\
73.7\end{array}$ & $\begin{array}{l}75 \\
75 \\
75 \\
75\end{array}$ & $\begin{array}{r}106.8 \\
101.7 \\
95.3 \\
98.3\end{array}$ \\
\hline $\mathrm{Cr}$ & . & $\ldots \quad \ldots$ & . & . & $\begin{array}{l}1 \\
2 \\
3\end{array}$ & $\begin{array}{l}5.93 \\
8.67 \\
10.4\end{array}$ & $\begin{array}{l}0.371 \\
0.267 \\
0.207\end{array}$ & $\begin{array}{l}183 \\
191 \\
179\end{array}$ & $\begin{array}{l}180 \\
180 \\
180\end{array}$ & $\begin{array}{r}101.7 \\
106.1 \\
99.4\end{array}$ \\
\hline
\end{tabular}

similar) confidence interval about the recovery value obtained. It is not possible to do this in a rigorous fashion for the results presented here as no statistically based method of curve fitting was used. However, it can be seen that if the value of $5 \%$ is taken as a guide, only one result falls outside $100 \pm$ $5 \%$ recovery. If the contributions to each recovery value are ignored, the mean and its $95 \%$ confidence interval calculated for the recovery values as given in the final columns of Tables 5 and 7 are $100.9 \%$ and $99.0-102.8 \%$.

\section{Conclusions}

It is possible to use a flow injection manifold for on-line dilution for calibration purposes and of sample solutions that are more concentrated than the top standard of a conventional calibration procedure. The method is rapid (after the dispersion coefficients of the manifold lines have been measured), convenient and free from bias. Re-calibration, either of the entire working range or by adjustment of the calibration function based on a single standard may be carried out rapidly. The method is compatible with present computer-based data handling and curve-fitting methods. The precision of the method is poorer than the conventional calibration procedure as the uncertainty in the calculated concentration includes a contribution from the uncertainty in the measured dispersion values. No evidence for these values being dependent on the concentration injected was found and thus no significant contribution from the instrument response function to the over-all dispersion was observed. This may mean that precision could be improved by measurement of the manifold dispersion coefficient values by an alternative technique, such as solution spectrophotometry. With the particular pump used no significant difference in flow-rate down any of the lines was observed and thus the calculated result should be independent of which line is used to produce the sample dilution.

As with all FI-AAS set-ups it is difficult to generalise from the results obtained with one particular combination of flow injection apparatus and AA spectrometer, particularly when the performance characteristics of the nebuliser are involved. However, the general concept of the variable dispersion coefficient manifold for calibration and dilution should be applicable to all FAA spectrometers.

Financial support for John Appleton from the S.E.R.C. and for James Mariara from the British Council is gratefully acknowledged.

\section{References}

1. Tyson, J. F., Analyst, 1985, 110, 419.

2. Fang, Z., Růžička, J., and Hansen, E. H., Anal. Chim. Acta, $1984,164,23$

3. Sweileh, J. A., and Cantwell, F. F., Anal. Chem., 1985, 57, 420.

4. Yamamoto, M., Yasuda, M., and Yamamoto, Y., Anal. Chem., 1985, 57, 1382.

5. Milosavljevic, E. B., Růžička, J., and Hansen, E. H., Anal. Chim. Acta, 1985, 169, 321.

6. Gallego, M., and Valcarcel, M., Anal. Chim. Acta, 1985, 169, 161.

7. Tyson, J. F., and Appleton, J. M. H., Anal. Proc., 1985, 22, 17

8. Tyson, J. F., Adeeyinwo, C. E., Appleton, J. M. H., Bysouth, S. R., Idris, A. B., and Sarkissian, L. L., Analyst, 1985, 110, 487.

9. Růžička, J., Stewart, J. W. B., and Zagatto, E. A. G., Anal. Chim. Acta, 1976, 81, 387.

10. Fernandez, A., Gomez-Nieto, M. A., Luque de Castro, M. D., and Valcarcel, M., Anal. Chim. Acta, 1984, 165, 217.

11. Appleton, J. M. H., and Tyson, J. F., J. Anal. At. Spectrom., 1986, 1, 63.

12. Miller, J. C., and Miller, J. N., "Statistics for Analytical Chemistry," Ellis Horwood, Chichester, 1984, p. 91.

13. Bysouth, S. R., and Tyson, J. F., J. Anal. At. Spectrom., 1986, 1, 85.

Paper J6/2

Received January 22nd, 1986 Accepted March 3rd, 1986 